Article

\title{
Gold Catalysts on Y-Doped Ceria Supports for Complete Benzene Oxidation
}

\author{
Lyuba Ilieva ${ }^{1, *}$, Petya Petrova ${ }^{1}$, Leonarda F. Liotta ${ }^{2, *}$, Janusz W. Sobczak ${ }^{3}$, Wojciech Lisowski ${ }^{3}$, \\ Zbigniew Kaszkur ${ }^{3}$, Gabriel Munteanu ${ }^{4}$ and Tatyana Tabakova ${ }^{1}$ \\ 1 Institute of Catalysis, Bulgarian Academy of Sciences, Acad. G. Bonchev St., Block 11, Sofia 1113, Bulgaria; \\ petia@ic.bas.bg (P.P.); tabakova@ic.bas.bg (T.T.) \\ 2 Istituto per lo Studio di Materiali Nanostrutturati (ISMN)-CNR, Palermo I-90146, Italy \\ 3 Institute of Physical Chemistry, Polish Academy of Sciences, Warsaw 01-224, Poland; \\ jsobczak@ichf.edu.pl (J.W.S.); wlisowski@ichf.edu.pl (W.L.); zkaszkur@ichf.edu.pl (Z.K.) \\ 4 Institute of Physical Chemistry, Romanian Academy, Bucharest 77208, Romania; g_munt@yahoo.com \\ * Correspondence: luilieva@ic.bas.bg (L.I.); leonarda.liotta@ismn.cnr.it (L.F.L.); Tel.: +3598-848-46-756 or \\ +3592-979-25-72 (L.I.); +3909-168-09-371 (L.F.L.); Fax: +3592-971-29-67 (L.I.); +3909-168-09-399 (L.F.L.)
}

Academic Editor: Salvatore Scirè

Received: 14 May 2016; Accepted: 1 July 2016; Published: 8 July 2016

\begin{abstract}
Gold (3 wt. \%) catalysts on Y-doped (1, 2.5, 5 and 7.5 wt. \% $\mathrm{Y}_{2} \mathrm{O}_{3}$ ) ceria supports prepared by coprecipitation (CP) or impregnation (IM) were studied in complete benzene oxidation (CBO). A low-extent $\mathrm{Y}$ modification was chosen to avoid ordering of oxygen vacancies. The samples were characterized by XRD, TGA, XPS and TPR techniques. A positive role of air pretreatment at $350{ }^{\circ} \mathrm{C}$ as compared to $200{ }^{\circ} \mathrm{C}$ was established for all Y-containing catalysts and it was explained by cleaning the active sites from carbonates. The oxygen supply cannot be considered as a limiting step for benzene oxidation except for the high 7.5\%-doped samples, as suggested by TGA and TPR data. On the basis of XPS results of fresh and used in CBO catalysts, the presence of cationic gold species does not seem important for high CBO activity. The gold catalyst on an IM support with 1\% Y-doping exhibited the best performance. A $100 \%$ benzene conversion was achieved only over this catalyst and $\mathrm{Au} /$ ceria, while it was not reached even at $300{ }^{\circ} \mathrm{C}$ over all other studied catalysts. Gold and ceria particle agglomeration or coke formation should be excluded as a possible reason, and the most probable explanation could be associated with the importance of the benzene activation stage.
\end{abstract}

Keywords: gold catalysts; Y-doped ceria; preparation method; pretreatment conditions; complete benzene oxidation

\section{Introduction}

Catalytic oxidation is considered one of the most promising technologies for the abatement of volatile organic compounds (VOCs) as hazardous and toxic air pollutants. A strong economic impact is related to the selection of catalysts with high activity and selectivity at relatively low temperatures. In a recent review by Scire and Liotta ([1] and references therein), gold-based catalysts were suggested as promising candidates for the total oxidation of VOCs. The influence of different factors, such as the nature and the properties of the support, the gold particle size and shape, the electronic state of the gold, the preparation method and the pretreatment conditions of catalysts, have been discussed in details. The authors summarized that the predominant opinion for the total oxidation of VOCs over gold supported on reducible oxides is that the reaction takes place thorough the Mars-van Krevelen mechanism with the participation of active oxygen supplied by the surface of the oxide support followed by reoxidation with the oxygen from the gas phase. A high activity could be expected for the readily reducible metal oxide supports. In this regard, ceria is a very appropriate support for gold 
catalysts, because of its ability to maintain a high gold dispersion and to take part in the oxidation reaction providing active oxygen species [2-6].

Aromatics are among the major families of VOCs from industrial and automotive emissions. Studies of nanosized gold on ceria-containing supports have revealed their successful use in the complete oxidation of benzene as a stable model aromatic molecule [7-13]. It is known that $\mathrm{CeO}_{2}$ modification with proper metal dopants leads to a defective structure (in particular the formation of oxygen vacancies), increasing the oxygen mobility in the ceria-based catalysts. Studying complete benzene oxidation (CBO) over gold catalysts on ceria doped with $\mathrm{MeO}_{x}(\mathrm{Me}=\mathrm{Fe}, \mathrm{Mn}, \mathrm{Co}$ and $\mathrm{Sn})$, Ilieva et al. [14] came to the conclusion that in some cases, independent of the easy oxygen provision enhanced by gold and ceria modification, the most essential factor responsible for the high oxidation activity could be related to the activation of the very stable benzene molecule.

In the present study, the impact of the Y-doping of ceria on the catalytic properties of gold ( $3 \mathrm{wt} . \%)$ catalysts on $\mathrm{CBO}$ was investigated. Gold over undoped $\mathrm{CeO}_{2}$ was used as a reference. Very recently, the catalytic performance in the preferential $\mathrm{CO}$ oxidation in the $\mathrm{H}_{2}$ reach stream (PROX) was studied over this type of gold catalyst [15]. In order to avoid the ordering of oxygen vacancies established in the literature for heavy yttrium doping ([16-18] and references therein), a low-extent $Y$ modification of ceria (up to 7.5 wt. $\% \mathrm{Y}_{2} \mathrm{O}_{3}$, i.e., 11 at. $\% \mathrm{Y}$ ) was chosen. Research on the use of Y-doped ceria as a support of gold catalysts in $\mathrm{CBO}$ has not been found in the reported literature. The aim of the study was to clarify the effect of the pretreatment procedure, the role of the state of the gold and the features of the differently prepared Y-doped ceria supports on the CBO activity.

\section{Results and Discussion}

\subsection{Catalytic Activity Measurements and TGA/QM Analysis}

The catalytic activity data in $\mathrm{CBO}$ are expressed as the temperature dependence of the benzene conversion degree. In all cases, the benzene oxidation was complete-no intermediate products of partial oxidation were detected.

The catalytic results of gold catalysts on or supports prepared by impregnation (IM) or coprecipitation (CP) with the same dopant amount after pretreatment in air at $200{ }^{\circ} \mathrm{C}$ or $350{ }^{\circ} \mathrm{C}$ are compared in Figure 1A.
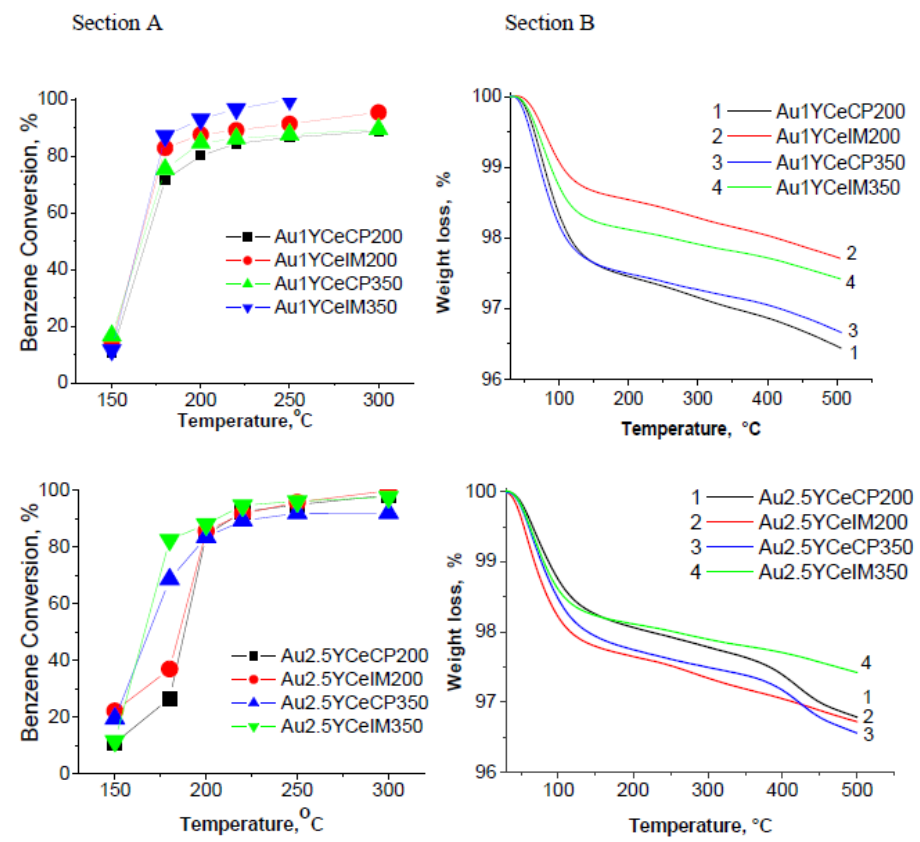

Figure 1. Cont. 
Section A
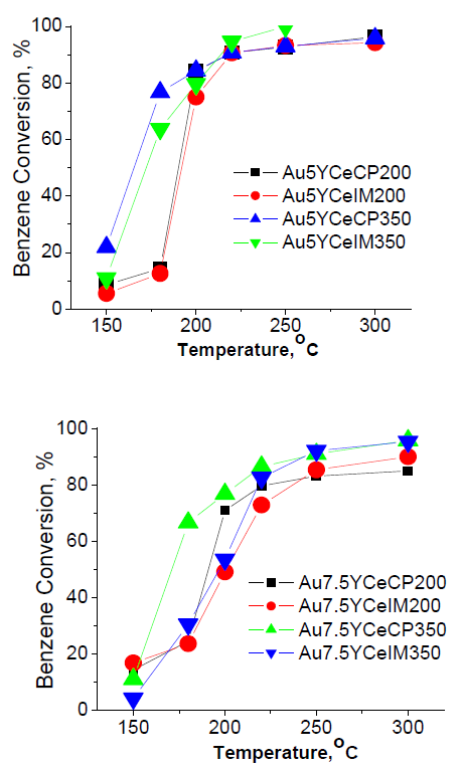

Section B
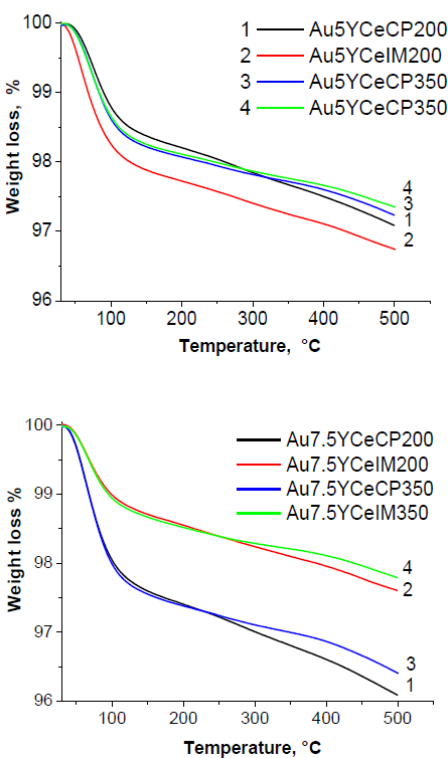

Figure 1. Section A: Comparison of the catalytic activity in complete benzene oxidation (CBO) over gold catalysts on ceria with different Y-doping after pretreatment in air at $200^{\circ} \mathrm{C}$ and $350{ }^{\circ} \mathrm{C}$; Section B: TPD results of the corresponding catalysts after oxygen adsorption at $200{ }^{\circ} \mathrm{C}$ or $350{ }^{\circ} \mathrm{C}$.

It is seen that the catalytic activity in $\mathrm{CBO}$ over gold catalysts on Y-doped ceria depends on the air pretreatment conditions: the positive role of the treatment at $350{ }^{\circ} \mathrm{C}$ is visible especially in the low temperature range. Unlike the registered $\mathrm{CBO}$ activities over the $\mathrm{Au} /$ ceria catalyst, which were quite the same, independent of the pretreatment temperature. The explanation could be related to the role of the pretreatment procedure for cleaning the active sites from carbonates. Differences in $\mathrm{CO}_{2}$ removal during heating in air of gold catalysts on bare ceria and Y-modified ceria were observed comparing the registered mass quadrupole spectra (QM ) spectra (TGA analysis step 2, Experimental Section). Generally, the $\mathrm{CO}_{2}$ evolution after heating in air at $350{ }^{\circ} \mathrm{C}$ was more intensive as compared to that at $200{ }^{\circ} \mathrm{C}$ for all Y-containing gold catalysts. The trend was more strongly expressed for the gold catalysts on IM as compared to the CP-prepared supports.

The results are illustrated in Figure 2, where (for the interest of space) only results pertaining to the selected Au1YCeIM (Figure 2A) and Au1YCeCP (Figure 2B) catalysts are given.

A

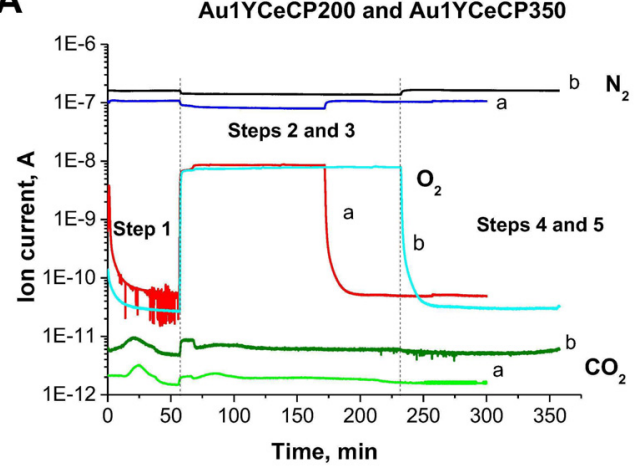

B

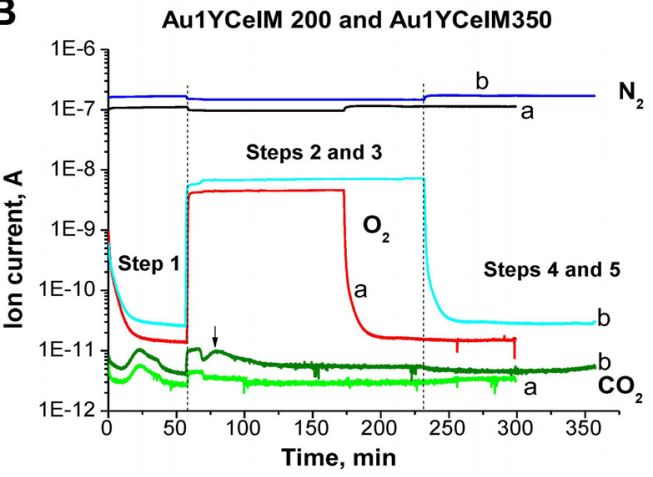

Figure 2. Cont. 


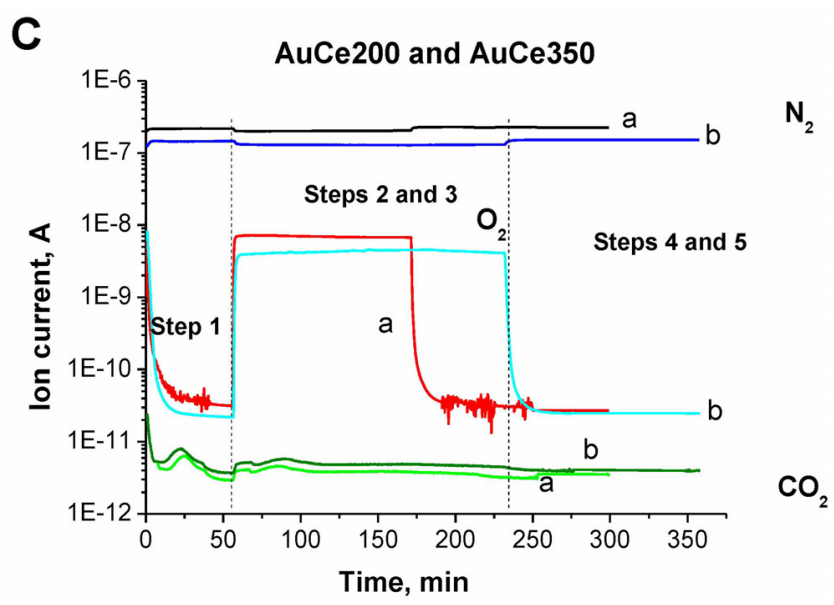

Figure 2. QM spectra of gaseous species $\mathrm{N}_{2}, \mathrm{O}_{2}$, and $\mathrm{CO}_{2}$ flowing during the TGA analyses carried out over the catalysts: (A) Au1YCeCP pretreated in air at $200{ }^{\circ} \mathrm{C}$ (a) and at $350{ }^{\circ} \mathrm{C}$ (b); (B) Au1YCeIM pretreated in air at $200{ }^{\circ} \mathrm{C}$ (a) and at $350{ }^{\circ} \mathrm{C}$ (b); (C) AuCe pretreated in air at $200{ }^{\circ} \mathrm{C}$ (a) or at $350{ }^{\circ} \mathrm{C}(\mathrm{b})$.

The similarity of the $\mathrm{CBO}$ activities of $\mathrm{Au} /$ ceria for both pretreatment temperatures is in agreement with the similar $\mathrm{CO}_{2} \mathrm{QM}$ signals registered for AuCe during air pretreatment at $200{ }^{\circ} \mathrm{C}$ and at $350{ }^{\circ} \mathrm{C}$ (see Figure 2C). The oxygen consumption peak is clearly visible at the beginning of step 2 for Au1YCeIM350 as well for Au1YCeCP200 samples, confirming that some oxygen is consumed from the gaseous phase. We do not see such consumption for AuCe200 and AuCe350, most probably because it is very small due to the lower amount of carbonate species in this case.

These observations are in accordance with the study of Vayssilov et al. [19]. On the basis of a combined density functional and IR spectroscopy investigation, the authors reported a stronger carbonate bond with the ceria surface having oxygen vacancies as compared to the surface free of vacancies. In our study, vacancy formation is caused by $\mathrm{Y}^{3+}$-doping; moreover, the vacancy generation by IM is mainly at the surface because this method of support preparation leads to the predominant surface modification of ceria [15]. The obtained TGA/QM data of the $\mathrm{CO}_{2}$ evolution could satisfactorily explain why the air treatment at $200{ }^{\circ} \mathrm{C}$ is enough for the cleaning of carbonates of the bare ceria surface but in the case of Y-doping a better effect appears after heating at the higher temperature.

Another reason for better activity after the higher-temperature treatment in air could be sought in the active oxygen supply. During the TGA measurements with air being introduced over the catalysts at $200{ }^{\circ} \mathrm{C}$ and $350{ }^{\circ} \mathrm{C}$, the $\mathrm{O}_{2}$ consumption peaks were detectable and the subsequent TPD experiments showed different amounts of oxygen desorption. The TGA curves, corresponding to step 5 (see the Experimental Section) are shown in Figure 1B for those catalysts for which CBO activity is respectively displayed in section A. A correlation between the catalytic activity and the amount of released oxygen, measured as weight loss (\%) versus temperature, is seen only for $7.5 \% \mathrm{Y}_{2} \mathrm{O}_{3}$ doping. The step of active oxygen supplying via the Mars-van Krevelen mechanism has to be related to the redox transfer $\mathrm{Ce}^{4+} \leftrightarrow \mathrm{Ce}^{3+}$, accompanied by the filling and emptying of the adjacent oxygen vacancies. It was already mention that in the present study, the variation of the $\mathrm{Y}$ amount was limited to 11 at. \% Y (7.5 wt. \% $\mathrm{Y}_{2} \mathrm{O}_{3}$ ) to avoid vacancy ordering in the case of heavy Y-doping above 10-15 at. \% [16-18]. However, clustering of $\mathrm{Y}^{3+}$ cations at the ceria surface cannot be excluded [20]. The surface microstructures of oxygen vacancies around clustered $\mathrm{Y}^{3+}$ cations with a stable valence state will not participate in the redox process, hindering the provision of oxygen. That is why the oxygen supplying could start to be a limiting step for the gold catalysts with a 7.5\% dopant amount. In the large excess of $\mathrm{O}_{2}$, the redox transfer $\mathrm{Ce}^{4+} \leftrightarrow \mathrm{Ce}^{3+}$ is a fast process and we do not see a correlation between TPD and the catalytic activity data for the catalysts with a lower $Y$ doping.

Figure 3 shows the comparison of $\mathrm{CBO}$ activity over the studied gold catalysts after air pretreatment at $350^{\circ} \mathrm{C}$. The catalytic activity at $150{ }^{\circ} \mathrm{C}$ is the highest for gold on bare ceria. Above this 
temperature the best performance is exhibited by the Au1YCeIM catalyst. The benzene conversion reached $100 \%$ at $250{ }^{\circ} \mathrm{C}$ for both Au1YCeIM and AuCe samples. The long-term experiment over Au1YCeIM catalyst at $250{ }^{\circ} \mathrm{C}$ during $24 \mathrm{~h}$ showed no decrease of the $100 \%$ benzene conversion. The catalytic behavior of other gold catalysts on Y-doped ceria, with the exception of Au7.5YCeIM (significantly worse activity up to $220^{\circ} \mathrm{C}$ ), did not differ very substantially and in all cases $100 \%$ conversion was not registered, even at $350{ }^{\circ} \mathrm{C}$.

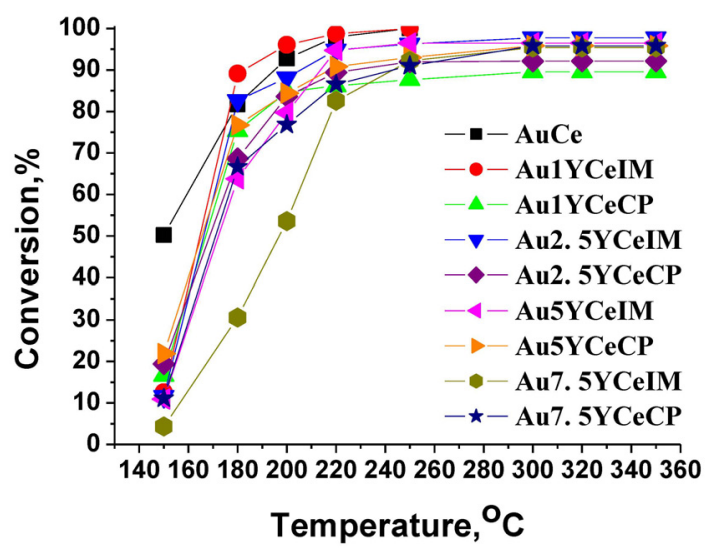

Figure 3. Catalytic activity in CBO after pretreatment in air at $350{ }^{\circ} \mathrm{C}$ over studied $\mathrm{Y}$-containing gold catalysts and AuCe.

\subsection{Sample Characterization}

The BET surface area and the average size of the ceria and gold crystallites estimated by XRD are given in Table 1. The surface area of AuCe is the highest one, and for the Y-containing samples it is in the range of $90-56 \mathrm{~m}^{2} \cdot \mathrm{g}^{-1}$; a tendency for lower values in the case of the highest $\mathrm{Y}$ amount in the supports prepared by both methods is seen.

Table 1. BET surface area $\left(\mathrm{S}_{\mathrm{BET}}\right)$, mean size $(\mathrm{D})$ of ceria and gold crystallites estimated by XRD.

\begin{tabular}{cccc}
\hline Sample & $\mathbf{S}_{\mathbf{B E T}}\left(\mathbf{m}^{\mathbf{2}} \cdot \mathbf{g}^{-\mathbf{1}}\right)$ & $\left.\mathbf{D}_{\mathbf{X R D}}\left(\mathbf{C e O}_{\mathbf{2}}\right) \mathbf{( n m}\right)$ & $\mathbf{D}_{\mathbf{X R D}}(\mathbf{A u})(\mathbf{n m})$ \\
\hline AuCe & 102.4 & $5.7(1)^{*}$ & 4.1 \\
Au1YCeIM & 87.2 & $7.1(6) / 6.7(1)^{\mathrm{a}}$ & $4.0 / 2.8 ; 5.1^{\mathrm{a}, \mathrm{b}}$ \\
Au2.5YCeIM & 83.2 & $5.3(8)$ & 3.7 \\
Au5YCeIM & 76.1 & $7.2(6)$ & 4.5 \\
Au7.5YCeIM & 55.9 & $6.7(2)$ & 3.2 \\
Au1YCeCP & 90.0 & $8.1(2) / 7.3(1)^{\mathrm{a}}$ & $5.8 / 5.7^{\mathrm{a}}$ \\
Au2.5YCeCP & 88.7 & $5.1(8)$ & 5.3 \\
Au5YCeCP & 82.4 & $4.3(8)$ & 5.4 \\
Au7.5YCeCP & 60.1 & $4.7(9)$ & 5.2 \\
\hline
\end{tabular}

* The numbers in brackets for $\mathrm{D}\left(\mathrm{CeO}_{2}\right)$ give the statistical error (determined as the error of regression) of the last figure of the number. For the $\mathrm{D}(\mathrm{Au})$ parameter, the error is difficult to estimate as the values resulted mostly from one peak (111), with the other (220) being barely visible; ${ }^{a}$ used catalyst; $^{b}$ bimodal distribution.

The X-ray diffractograms of all catalysts (Figure 4, upper section) were similar, showing only the diffraction lines of the cubic crystal structure of ceria and very weak reflections at $2 \Theta=38.2^{\circ}$, typical of metallic $\mathrm{Au}$ (1 11 1). A second phase of $\mathrm{Y}_{2} \mathrm{O}_{3}$ was not visible; however, the presence of $\mathrm{Y}_{2} \mathrm{O}_{3}$ crystals not detectable by XRD for the IM-prepared supports was evidenced by measuring the interplanar distances in selected HRTEM images [15]. The estimated average size of ceria crystallites was in the range of 4-8 nm (Table 1), without a clear dependence on the support preparation method and the $\mathrm{Y}$ amount. 


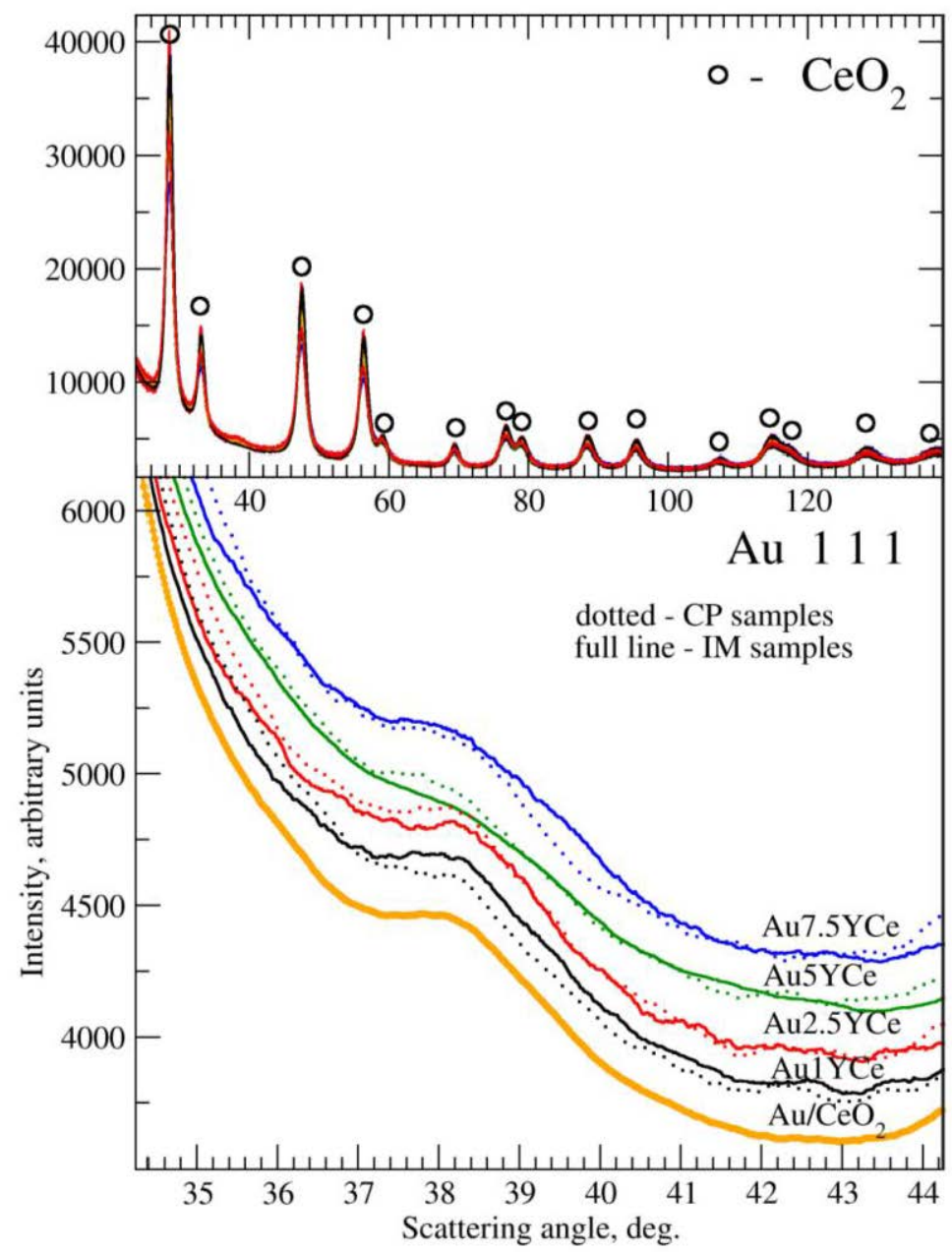

Figure 4. Close up of the $\left(\begin{array}{lll}1 & 1 & 1\end{array}\right)$ peaks of gold in the XRD patterns of the studied gold catalysts. Inset shows the similarity in the X-ray diffractograms of all catalysts is illustrated.

A close-up of the (1 111 ) peaks of gold is presented in the lower section of Figure 4. It is seen that the evaluation of the gold crystallite size requires proper background estimation and some notable differences in the previously reported data [15] could be attributed to the background assessment. In the current evaluation resulting in the Table 1 data, all peaks in the background were chosen in a consistent way: the ceria reflections were fitted to doublets of Pearson VII analytical peak-shape corresponding to $K_{\alpha 1}$ and $K_{\alpha 2}$ constituents (2:1) of the $K_{\alpha}$ copper emission line and the remaining background to a smooth polynomial function. The background could be slightly modified to assure a perfect fit and the procedure iterated. The background of Au peaks appeared thus naturally as superimposed slopes of the neighboring ceria peaks. For each pattern, the possibility of a bimodal size distribution with a broad intensity contribution over a wide angular range was tested for a stable fit.

The similarity in the average size of gold for all catalysts (Table 1) is consistent with the statistically obtained values on the basis of HRTEM measurements in a previous study [15]. Through a careful analysis of HRTEM and Z contrast (HAADF) images, reliable particle size measurements were made in order to obtain the size distribution histograms and the average size of the gold crystallites. The results showed highly dispersed gold with similar average particle sizes in the range of 2.1-3.5 nm (in some cases the quantity of highly dispersed gold was accompanied by rarely distributed crystallites bigger than $10 \mathrm{~nm})$ [15].

The ceria and especially gold agglomeration during the catalytic work could be a possible reason for the observed experimental fact that, except for the AuCe and Au1YCeIM catalysts, the 100\% 
conversion was not registered even at $350^{\circ} \mathrm{C}$ over all the other samples. Studying different $\mathrm{Au} /$ ceria catalysts in complete benzene oxidation, Ying et al. [21] reported that the sintering of gold under reaction conditions easily caused deactivation. In the present investigation, the eventual ceria or gold particle agglomeration during the catalytic work was checked. The results of XRD measurements with the Au1YCeIM and Au1YCeCP catalysts used in CBO are also given in Table 1. A slight decrease in the average size of the ceria crystallites was observed. The explanation could be similar to the already-reported observation related to the Pr-doped ceria supports: an increased number of small nanocrystals of ceria detectable by XRD is built up from the previously amorphous part of the fresh material, thus shifting the average size of the ceria in the used sample towards a lower value; the suggestion was proved by means of TEM measurements [22]. The XRD data for the used Au1YCeIM showed a bimodal distribution of gold crystallites, while for the less active Au1YCeCP, the gold's average size after catalytic work was practically the same as the fresh catalyst. The results reveal that neither ceria nor gold particle agglomeration could be the reason for the noted differences in $\mathrm{CBO}$ activities.

The reducibility of the samples was evaluated by means of TPR measurements. The reduction of ceria proceeds in two steps: the reduction of the surface layers at around $500{ }^{\circ} \mathrm{C}$ and the bulk reduction at higher temperatures (over $800^{\circ} \mathrm{C}$ ) [23]. Since the first reports 15 years ago [24,25], many studies have shown that the addition of nanosized gold causes a significant temperature lowering of the reduction of ceria surface layers.

In Figure 5A-D, the TPR profiles related to the surface reduction of the studied gold catalysts are compared in the low-temperature interval which is of interest for catalysis.
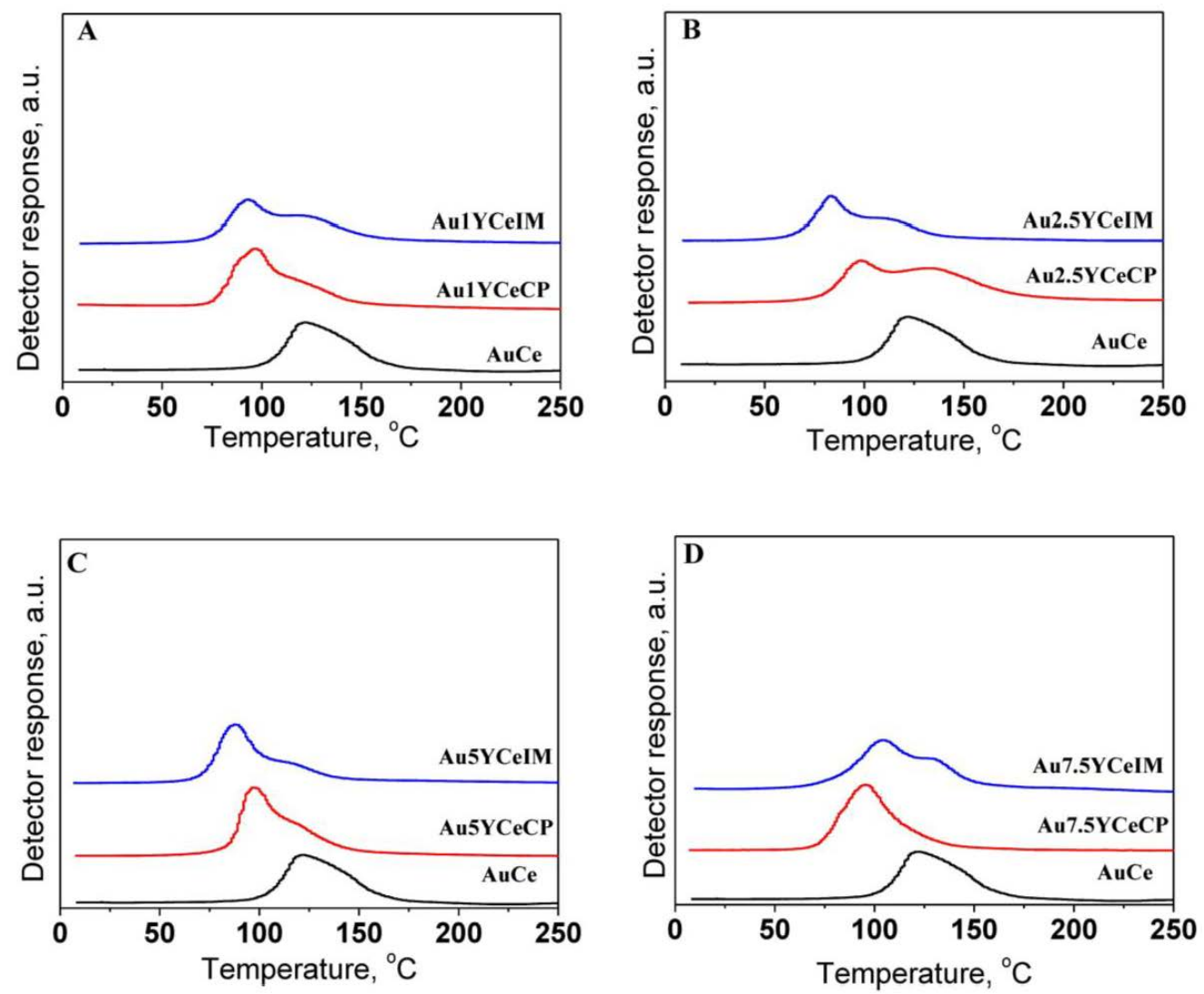

Figure 5. TPR profiles of the studied gold catalysts in the temperature interval of ceria surface layer reduction: (A) Catalysts containing $1 \mathrm{wt}$. \% dopant and AuCe as a reference; (B) Catalysts containing 2.5 wt. \% dopant and AuCe as a reference; (C) Catalysts containing 5 wt. \% dopant and AuCe as a reference; (D) Catalysts containing 7.5 wt. \% dopant and AuCe as a reference. 
The TPR profile of gold/ceria is shown as a reference. The TPR peaks related to the ceria surface reduction of all gold catalysts on Y-doped ceria did not differ very significantly. They are complex, composed of lower- and higher-temperature parts, with the last one located in the temperature range of the AuCe surface reduction. This result of the partially enhanced reduction of Au/doped ceria is indicated in the role of $\mathrm{Y}$ modification. A tendency for a lower first $\mathrm{T}_{\max }$ for the catalysts on IM-prepared supports as compared to the $\mathrm{CP}$ preparation is visible (except for the $7.5 \mathrm{wt}$. \% dopant amount). This should be due to the effect of gold with a slightly lower average size (Table 1) as well as to the easy oxygen removal in the case of the IM method leading to a predominant surface modification (proven by Raman spectroscopy results [15]). The observed difference for the sample on the IM-prepared support with $7.5 \mathrm{wt}$. \% doping could be ascribed to the higher amount of the separate unreducible $\mathrm{Y}_{2} \mathrm{O}_{3}$ phase caused by this method of preparation (evidenced by HRTEM [15]) which hinders the ceria surface reduction. Below, the reduction processes related to the Au7.5YCeIM and Au7.5YCeCP catalysts are considered in more detail.

The theoretical values of hydrogen consumption for the reduction of ceria surface layers according to literature data are limited to $17 \%$ [26] or $20 \%$ [27]. It means that there is a stoichiometric $\mathrm{H}_{2}$ consumption of $0.49-0.58 \mathrm{mmol} \cdot \mathrm{g}^{-1}$ for pure ceria and a stoichiometric $\mathrm{H}_{2}$ consumption in the range of $0.49-0.57 \mathrm{mmol} \cdot \mathrm{g}^{-1}$ to $0.46-0.54 \mathrm{mmol} \cdot \mathrm{g}^{-1}$ for the ceria doped with $1-7.5 \mathrm{wt}$. \% $\mathrm{Y}_{2} \mathrm{O}_{3}$, respectively. The $\mathrm{H}_{2}$ consumption for some positively charged reduction of gold particles is negligible and can be ignored. The values of $\mathrm{H}_{2}$ consumption evaluated on the basis of experimentally obtained TPR data are given in Table 2.

Table 2. Experimental $\mathrm{H}_{2}$ consumption calculated for the temperature range characteristic for ceria surface layer reduction of the studied gold catalysts.

\begin{tabular}{ccc}
\hline \multirow{2}{*}{ Catalysts } & \multicolumn{2}{c}{$\mathbf{H}_{\mathbf{2}}$ Consumption $\left(\mathbf{m m o l} \cdot \mathbf{g}^{-\mathbf{1}}\right.$ ) } \\
\cline { 2 - 3 } & $\mathbf{C P}$ & $\mathbf{I M}$ \\
\hline AuCe & & 0.54 \\
Au1YCe & 0.69 & \\
Au2.5YCe & 0.87 & 0.62 \\
Au5YCe & 0.80 & 0.59 \\
Au7.5YCe & 0.78 & 0.61 \\
\hline
\end{tabular}

The $\mathrm{H}_{2}$ consumption of AuCe equal to $0.54 \mathrm{mmol} \cdot \mathrm{g}^{-1}$ corresponds to $18.7 \%$ of the total $\mathrm{H}_{2}$ amount needed for ceria reduction. All gold catalysts on Y-doped ceria show a participation in the reduction process of some oxygen coming from the bulk layers (experimental $\mathrm{H}_{2}$ consumption $>20 \%$ degrees of reduction). Besides, a tendency of relatively higher $\mathrm{H}_{2} \mathrm{C}$ in the case of the $\mathrm{CP}$ method as compared to the IM mode of preparation can be seen in Table 2.

The explanation was sought in the differences in the Y-doped ceria structure depending on the method of the synthesis of supports. For keeping the neutrality in the case of the surface layer $\mathrm{Y}^{3+}$ enrichment of IM-prepared supports, a bigger amount of oxygen vacancies is created and it causes: (i) improved oxygen mobility related to the above-mentioned first $\mathrm{T}_{\max }$ in the TPR; (ii) less oxygen in the ceria surface layers available for the reduction process, leading to the observed lower $\mathrm{H}_{2}$ consumption of gold catalysts on IM as compared to CP supports. Despite the systematically lower oxygen supply of the IM samples, the CBO performance of Au1YCeIM was better than that of the Au1YCeCP catalyst (Figure 3) and no substantial activity differences depending on the preparation method were observed for the gold catalysts with 1, 2.5 and 5 wt. $\% \mathrm{Y}_{2} \mathrm{O}_{3}$. The observations are in accordance with the above-discussed relationship between catalytic and $\mathrm{O}_{2}$-TPD results, guiding us to the supposition that the provision of oxygen was not a limiting step for the catalysts with these dopant amounts. The oxygen supply became important only for the case of $7.5 \%$ doping. Correspondingly, especially in the low temperature range, the $\mathrm{CBO}$ activity over gold catalysts with this $\mathrm{Y}$ concentration depends on the preparation method: a higher benzene conversion over Au7.5YCeCP than that over 
the Au7.5YCeIM sample was registered (Figure 3). A relevant explanation should be connected to the reducibility of the catalysts. The TPR behavior in this case was studied in more detail. Each complex TPR process related to the gold catalysts on the $7.5 \%$ Y-doped support prepared by IM or CP had been simulated considering the equation for the rate of the reduction [28]. The TPR profiles of Au7.5YCeIM (Figure 6A) and Au7.5YCeCP (Figure 6B; it is visible that the peak is not single as it is not symmetric), as well as that of all Y-doped catalysts prepared either by the IM or by CP method, were complex. They were deconvoluted into peaks respective to the individual reduction processes (dotted lines). A good fit between the computed (full line) and the experimental TPR curve (bold full line) could be achieved, taking into consideration the two individual processes. This means that there are two types of oxygen which have different mobilities, and the eventual reason could be their different distances to the gold and/or to $\mathrm{Y}^{3+}$ with the created oxygen vacancies. The corresponding two peaks have different intensities but their relative parts are $60 \%$ and $40 \%$ for both the Au7.5YCeIM and Au7.5YCeCP samples. The difference between Au7.5YCeIM and Au7.5YCeCP catalysts is seen in comparing the $\mathrm{T}_{\max }$. In the case of the $\mathrm{CP}$ method, the reduction processes of the ceria surface layers occur with almost the same $\mathrm{T}_{\max }$ at about $95^{\circ} \mathrm{C}$. For Au7.5YCeIM, oxygen with a different facility of surface reduction ( $\mathrm{T}_{\max }$ of the second peak was at a higher temperature, at around $130^{\circ} \mathrm{C}$ ) exists.
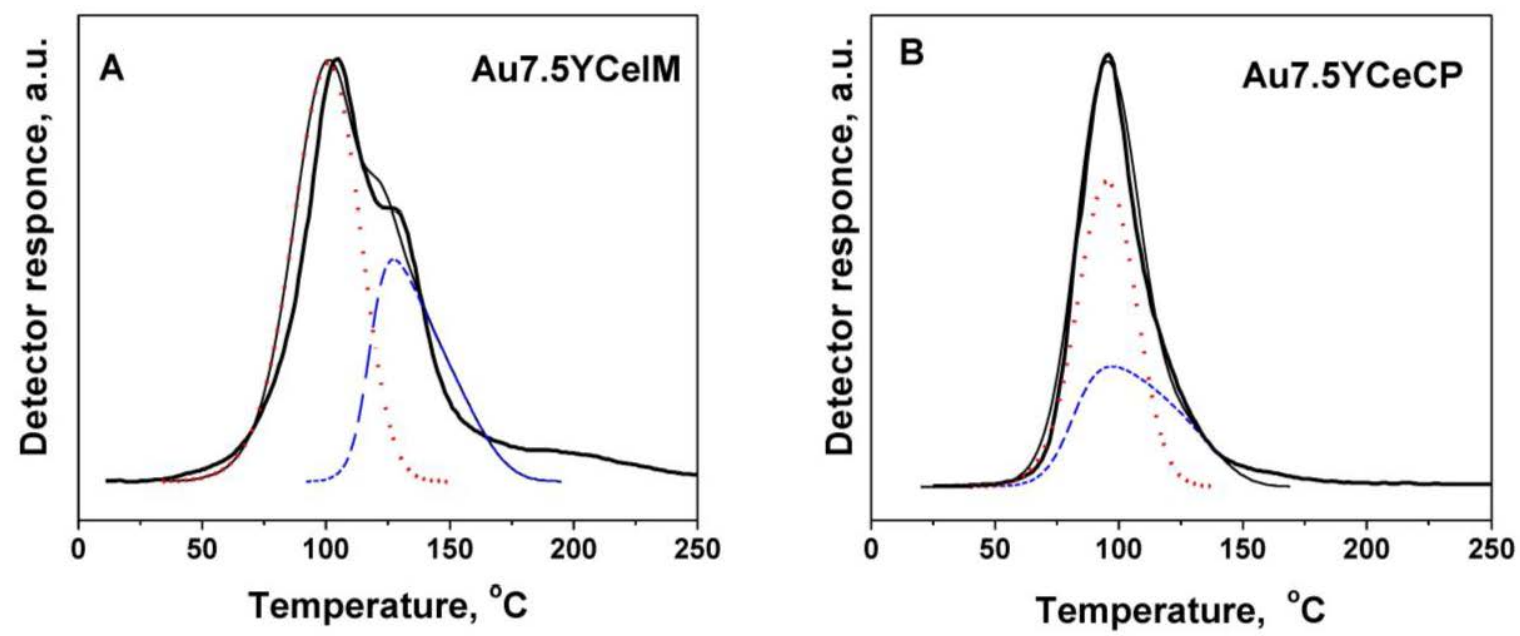

Figure 6. TPR profiles of Au7.5YCeIM (A) and Au7.5YCeCP catalysts (B): full lines-experimental curve (bold) and fitted calculated curve, dotted lines-peaks corresponding to the individual reduction processes.

The separate unreducible $\mathrm{Y}_{2} \mathrm{O}_{3}$ phase formed by IM preparation on the ceria surface with a higher $\mathrm{Y}^{3+}$ concentration could cause both the lower reducibility (see also the $\mathrm{H}_{2}$ consumption in Table 2) and oxidation activity of the Au7.5YCeIM catalyst. The eventual positive role of nanosized $\mathrm{Au} / \mathrm{Y}_{2} \mathrm{O}_{3}$ with a contribution to the $\mathrm{Au} /$ modified ceria reactivity is expected for the $1 \%$ doping, as a phase of bigger particles could be formed by a higher $\mathrm{Y}$ concentration. Actually, the highest $\mathrm{CBO}$ activity was registered over the Au1YCeIM catalyst; this was the only sample with a better CBO performance as compared to gold on bare ceria. In agreement, Guzman and Corma have established that nanocrystalline $\mathrm{Y}_{2} \mathrm{O}_{3}$ stabilized active species of gold and increased the $\mathrm{CO}$ oxidation activity [29]. Low total ethyl acetate and toluene oxidation activity have been reported by Carabineiro et al. [30] for gold supported on commercial $\mathrm{Y}_{2} \mathrm{O}_{3}$ (big average crystallite size of $43 \mathrm{~nm}$ ).

The correlation between the state of the gold species and the activity in the total VOCs oxidation is still under debate [1]. The participation of cationic gold in VOCs oxidation has been proposed by several authors, whereas a predominant role of gold in the metallic state has been reported by another research group. An opinion that the Au electronic state does not significantly influence the catalytic activity, because the role of gold is secondary to that of the support, also exists ([1] and references 
therein). Andreeva et al. [9] have found that $\mathrm{Au} / \mathrm{CeO}_{2}, \mathrm{Au} / \mathrm{MoO}_{x} / \mathrm{CeO}_{2}$, and $\mathrm{Au} / \mathrm{MoO}_{x} / \mathrm{CeO}_{2}-\mathrm{Al}_{2} \mathrm{O}_{3}$ fresh catalysts contained exclusively $\mathrm{Au}^{0}$, whereas some positively charged gold was present on the $\mathrm{AuCeAl}$ catalysts, found to be less active in the benzene oxidation. In the present study, the XPS measurements were performed with selected gold catalysts representing the best (Au1YCeIM) and poorest (Au1YCeCP) catalytic behavior. The high-resolution (HR) XP spectra of $A u 4 f_{7 / 2}, C e 3 d_{5 / 2}$ and $\mathrm{C}$ 1s were recorded for both catalysts: fresh, in situ oxidized following the oxidative pre-treatment procedure at $350{ }^{\circ} \mathrm{C}$, and used in CBO. The HR spectra analysis data are illustrated in Table 3. The Au 4f spectra recorded on corresponding samples are compared in Figure 7. For both fresh catalysts the positively charged $\mathrm{Au}$ species $\left(\mathrm{Au}^{\delta+}\right)$ with a binding energy $(\mathrm{BE})$ higher than $85.0 \mathrm{eV}$ were detected in addition to metallic gold $\left(\mathrm{Au}^{0}\right)$ with a $\mathrm{BE}$ of $84.1-84.2 \mathrm{eV}$ (Figure 6A,D, respectively). The relative contribution of $\mathrm{Au}^{\delta+}$ species in the Au1YCeIM catalyst was lower than in the Au1YCeCP sample. The slightly lower content of $\mathrm{Au}^{\delta+}$ species after the Au1YCeIM oxidative treatment could be explained by the agglomeration of some very small Au particles. This supposition is well supported by full wight at half maximum (FWHM) values of the recorded Au 4f peaks: 1.69 for the fresh Au1YCeIM sample and 1.44 after its oxidative treatment. The lower FWHM value indicates a smaller dispersion of $\mathrm{Au}$ nanoparticles after the oxidation procedure. The $\mathrm{Au}^{\delta+}$ amounts evaluated for both samples were found to be similar. However, for the Au1YCeCP sample a small contribution (3.5\%) of Au species at a higher $\mathrm{BE}$, assigned to the $\mathrm{Au}^{3+}$ species, was registered as well (Table 3).

Table 3. XPS data of the studied samples.

\begin{tabular}{|c|c|c|c|c|c|c|c|c|c|c|}
\hline \multirow{2}{*}{ Catalyst } & \multicolumn{2}{|c|}{$\mathrm{Au} 4 \mathrm{f}_{7 / 2}$} & \multicolumn{2}{|c|}{ Ce $3 d_{5 / 2}\left(\mathrm{Ce}^{3+}\right)$} & \multicolumn{2}{|l|}{ O 1s } & \multicolumn{2}{|c|}{ C 1s } & \multirow[t]{2}{*}{$\mathrm{Au} / \mathrm{Ce}$} & \multirow[t]{2}{*}{$\mathrm{Y} / \mathrm{Ce}$} \\
\hline & BE (eV) & Area $(\%)$ & $\mathrm{BE}(\mathrm{eV})$ & (at. \%) & BE $(e V)$ & (at. \%) & BE $(e V)$ & (at. \%) & & \\
\hline \multirow{4}{*}{$\begin{array}{l}\text { Au1YCeIM } \\
\text { as received }\end{array}$} & \multirow{4}{*}{$\begin{array}{c}84.07\left(\mathrm{Au}^{0}\right) \\
85.59\left(\mathrm{Au}^{\delta+}\right)\end{array}$} & \multirow{4}{*}{$\begin{array}{l}81.8 \\
18.2\end{array}$} & \multirow{4}{*}{$\begin{array}{l}880.73 \\
884.53\end{array}$} & \multirow{4}{*}{35.7} & \multirow{4}{*}{$\begin{array}{l}529.46\left(\mathrm{O}^{2-}\right) \\
531.89(-\mathrm{OH})\end{array}$} & \multirow{4}{*}{$\begin{array}{l}45.6 \\
15.2\end{array}$} & \multirow{4}{*}{$\begin{array}{c}285.22 \\
(\mathrm{C}-\mathrm{C}, \mathrm{C}-\mathrm{H}) \\
286.72(\mathrm{C}-\mathrm{OH}) \\
288.22(\mathrm{C}=\mathrm{O})\end{array}$} & 12.6 & \multirow{4}{*}{0.022} & \multirow{4}{*}{0.041} \\
\hline & & & & & & & & 2.2 & & \\
\hline & & & & & & & & 1.6 & & \\
\hline & & & & & & & & $\Sigma=16.4$ & & \\
\hline \multirow{4}{*}{$\begin{array}{l}\text { Au1YCeIM } \\
\text { oxidized at } \\
350^{\circ} \mathrm{C}\end{array}$} & \multirow{4}{*}{$\begin{array}{c}84.10\left(\mathrm{Au}^{0}\right) \\
85.63\left(\mathrm{Au}^{\delta+}\right)\end{array}$} & \multirow{4}{*}{$\begin{array}{l}84.4 \\
15.6\end{array}$} & \multirow{4}{*}{$\begin{array}{l}880.68 \\
884.11\end{array}$} & \multirow{4}{*}{28.4} & \multirow{4}{*}{$\begin{array}{l}529.49\left(\mathrm{O}^{2-}\right) \\
531.64(-\mathrm{OH})\end{array}$} & \multirow{4}{*}{$\begin{array}{l}49.0 \\
12.0\end{array}$} & 285.27 & 10.1 & \multirow{4}{*}{0.022} & \multirow{4}{*}{0.042} \\
\hline & & & & & & & $(\mathrm{C}-\mathrm{C}, \mathrm{C}-\mathrm{H})$ & 1.0 & & \\
\hline & & & & & & & $286.77(\mathrm{C}-\mathrm{OH})$ & 2.9 & & \\
\hline & & & & & & & $288.27(\mathrm{C}=\mathrm{O})$ & $\Sigma=14.2$ & & \\
\hline \multirow{3}{*}{$\begin{array}{c}\text { Au1YCeIM } \\
\text { used in CBO }\end{array}$} & \multirow{3}{*}{$83.88\left(\mathrm{Au}^{0}\right)$} & \multirow{3}{*}{100} & \multirow{3}{*}{$\begin{array}{l}880.78 \\
885.05\end{array}$} & \multirow{3}{*}{33.6} & & & 285.15 & 8.9 & & \\
\hline & & & & & $529.48\left(\mathrm{O}^{2-}\right)$ & 51.4 & $(\mathrm{C}-\mathrm{C}, \mathrm{C}-\mathrm{H})$ & 0.7 & 0.019 & 0.035 \\
\hline & & & & & $531.82(-\mathrm{OH})$ & 13.1 & $286.50(\mathrm{C}-\mathrm{OH})$ & $\Sigma=9.6$ & & \\
\hline & & & & & & & 285.00 & 8.8 & & \\
\hline Au1YCeCP & & & & & & & (C-C,C-H) & 3.7 & & \\
\hline as received & $\begin{array}{c}84.20\left(\mathrm{Au}^{ }\right) \\
85.18\left(\mathrm{Au}^{\delta+}\right)\end{array}$ & 41.3 & 885.13 & 30.9 & $\begin{array}{l}529.54\left(\mathrm{U}^{-}\right) \\
531.85(-\mathrm{OH})\end{array}$ & 13.9 & $286.35(\mathrm{C}-\mathrm{OH})$ & 0.4 & 0.023 & 0.029 \\
\hline & & & & & $533.31(\mathrm{C}-\mathrm{O}-\mathrm{C})$ & 3.1 & $287.76(\mathrm{C}=\mathrm{O})$ & $\Sigma=12.9$ & & \\
\hline & & & & & & & 285.01 & 5.0 & & \\
\hline & $84.05\left(\mathrm{Au}^{0}\right)$ & & & & & & $(\mathrm{C}-\mathrm{C}, \mathrm{C}-\mathrm{H})$ & 4.6 & & \\
\hline oxidized at & $85.01\left(\mathrm{Au}^{\delta+}\right)$ & $\begin{array}{l}40.0 \\
3.5\end{array}$ & 884.64 & 27.0 & $531.71(-\mathrm{OH})$ & 11.9 & $285.70(\mathrm{C}-\mathrm{OH})$ & 0.2 & 0.024 & 0.026 \\
\hline & $86.25\left(\mathrm{Au}^{3+}\right)$ & & & & & & $287.77(\mathrm{C}=\mathrm{O})$ & $\Sigma=9.8$ & & \\
\hline & & & & & & & & 12.4 & & \\
\hline Au1YCeCP & $83.90\left(\mathrm{Au}^{0}\right)$ & 90.3 & 880.24 & 288 & $529.45\left(\mathrm{O}^{2-}\right)$ & 30.0 & $(\mathrm{C}-\mathrm{C}, \mathrm{C}-\mathrm{H})$ & 8.9 & ? & \\
\hline used in CBO & $85.25\left(\mathrm{Au}^{\delta+}\right)$ & 9.7 & 885.09 & 28.8 & $532.64(-\mathrm{OH})$ & 29.0 & $286.51(\mathrm{C}-\mathrm{OH})$ & 4.2 & 0.022 & 0.076 \\
\hline & & & & & & & $289.51(\mathrm{COOH})$ & $\Sigma=25.4$ & & \\
\hline
\end{tabular}

After the catalytic test in CBO, only metallic gold was detected for the highly active Au1YCeIM used catalyst (Figure 7C), while some amount of positively charged gold species was evidenced for the spent, less active Au1YCeCP (Figure 7F). In relation to the unresolved question about the role of the state of the gold, these results revealed that the cationic gold species cannot be supposed as important for high $\mathrm{CBO}$ activity.

Both $\mathrm{Ce}^{4+}$ and $\mathrm{Ce}^{3+}$ surface cations exist in all studied catalysts. As expected, the contribution of $\mathrm{Ce}^{3+}$ was relatively lower after the oxidative treatment. Comparing the used Au1YCeIM and Au1YCeCP samples, the ceria surface of the spent, less active Au1YCeCP catalyst was reduced to a relatively lower extent $\left(28.8\right.$ at. $\left.\% \mathrm{Ce}^{3+}\right)$ as compared to the highly active Au1YCeIM $\left(33.6\right.$ at. $\left.\% \mathrm{Ce}^{3+}\right)$. 
With respect to the surface atomic ratios in all studied catalysts, the amount of surface gold is a little less than the nominal one (0.03). The $\mathrm{Y} / \mathrm{Ce}$ atomic ratios are larger than the analytical one (0.016), showing ceria surface enriched by $\mathrm{Y}^{3+}$ This effect is stronger for the fresh and air-pretreated Au1YCeIM as compared to the Au1YCeCP catalyst, in agreement with the IM preparation leading to the predominant surface modification and a separate $\mathrm{Y}_{2} \mathrm{O}_{3}$ phase. However, surprisingly, the $\mathrm{Y} / \mathrm{Ce}$ ratio in the Au1YCeCP sample used in $\mathrm{CBO}$ is very high (0.076) - different from the sample on the IM support (0.035), the catalytic work caused a significant $Y^{3+}$ segregation at the Au1YCeCP surface.

The spectra in the $\mathrm{O} 1 \mathrm{~s}$ region could be separated in two contributions due to the lattice oxygen (a BE between 529.0 and $530.3 \mathrm{eV}$ [31]) and hydroxyl species (except fresh Au1YCeCP with a supplemental small contribution of oxygen in the $\mathrm{C}-\mathrm{O}-\mathrm{C}$ bond). Fewer $-\mathrm{OH}$ groups were detected after the pretreatment in air at $350^{\circ} \mathrm{C}$ but they still exist; for ceria, the elimination of residual hydroxyls through thermal decomposition under air requires a relatively high temperature (above $600{ }^{\circ} \mathrm{C}$ [31]). In both fresh Au1YCeIM and Au1YCeCP catalysts, the at. \% of the lattice oxygen is comparable (45.6 and $47.0 \%$, respectively). The treatment in air at $350{ }^{\circ} \mathrm{C}$ leads to its increase-slightly higher in the case of the CP support. Interestingly, in the used Au1YCeIM catalyst highly active in CBO, the oxygen amount is kept the same as in the air-pretreated initial sample, while in the case of less active Au1YCeCP, it is significantly lower (only 30 at. \%). It means that the surface reoxidation in the last case is hard up and this could be one of the reasons for the lower oxidation activity. The observation is in agreement with the above-drawn conclusion for the $\mathrm{Y}$ segregation at the Au1YCeCP surface. It means that there is enrichment by unreducible $\mathrm{Y}^{3+}$ ions surrounded by oxygen vacancies which do not participate in the reoxidation process, resulting in the lack of oxygen supply.
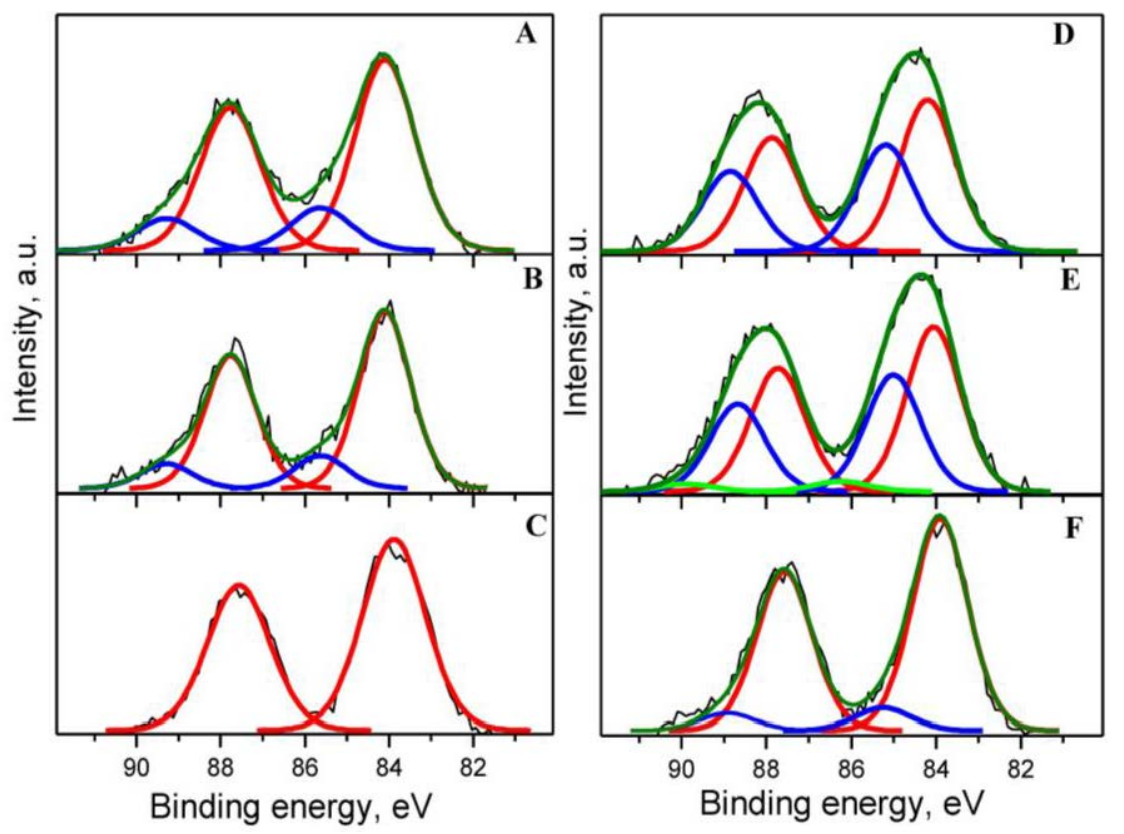

Figure 7. Comparison of experimental and fitted Au 4f XPS spectra of: (A) Au1YCeIM as received; (B) Au1YCeIM in situ oxidized at $350^{\circ} \mathrm{C}$; (C) Au1YCeIM used in CBO; (D) Au1YCeCP as received; (E) Au1YCeCP in situ oxidized at $350^{\circ} \mathrm{C}$; and (F) Au1YCeCP used in CBO.

A careful analysis of $C$ 1s spectra revealed the coexistence of various carbon-like species at the surface of both measured fresh catalysts (see Table 3). However, it is not possible to discuss the presence of carbonates using the XPS spectra as it is known that the BE position of carbon in carbonate species $(\mathrm{COOH})$ is within the range of 288.4 to $290 \mathrm{eV}$ and it is overlapped with the broad Ce 4s peak of 289.4 to $289.7 \mathrm{eV}$ [31-33]. It is interesting to note that the total amount of $\mathrm{C}$ in the less active Au1YCeCP catalyst used in $\mathrm{CBO}$ is considerably higher than in the corresponding Au1YCeIM sample (25.4 and 9.6 at. \%, 
respectively). One possible reason for the observed course of the Au1YCeCP benzene conversion curve (no 100\% conversion reached) could be related to the coke formation. Unfortunately, in the $\mathrm{C}$ 1s XPS spectra fitting it appeared impossible to distinguish the carbon originating from coke and other C-like surface contaminants in any reasonable way. EPR measurements were performed with used Au1YCeIM and Au1YCeCP catalyst in order to clarify this issue. The attention was focused on the signal related to the presence of coke. Even in the 10-fold increased EPR spectra at $-150{ }^{\circ} \mathrm{C}$, in the magnetic field range of 320-335 $\mathrm{mT}$, no signal at $\mathrm{g}=2.003$ due to carbon radicals [34] was detected for either of the spent samples, thereby excluding coke formation as a reason for the different catalytic properties.

On the basis of all the obtained results, the most probable explanation of the established catalytic behavior of gold catalysts on Y-modified ceria in CBO with regard to $100 \%$ benzene conversion could be associated with: (i) the importance of surface reoxidation during the redox process of $\mathrm{CBO}$; (ii) the importance of the benzene activation stage. It is in agreement with the previously discussed suggestion [14] that depending on the catalytic system, the key factor for the high oxidation activity could not be the oxygen supply but the activation of the very stable benzene molecule.

\section{Experimental Section}

\subsection{Sample Preparation}

Two different methods, namely wet impregnation (IM) and co-precipitation (CP), were used for preparation of $\mathrm{Y}$-doped ceria supports $\left(1,2.5,5\right.$ and $7.5 \mathrm{wt}$. \% of $\left.\mathrm{Y}_{2} \mathrm{O}_{3}\right)$. Bare ceria was synthesized by precipitation of aqueous solutions of cerium(III) nitrate (Sigma-Aldrich GmbH, Buchs, Switzerland) with solution of $\mathrm{K}_{2} \mathrm{CO}_{3}$ (Sigma-Aldrich $\mathrm{GmbH}$ ) keeping constant temperature $\left(60^{\circ} \mathrm{C}\right.$ ) and $\mathrm{pH}$ (9.0). Using IM method ceria was impregnated with aqueous solutions of calculated amounts of $\mathrm{Y}\left(\mathrm{NO}_{3}\right)_{3} \cdot 6 \mathrm{H}_{2} \mathrm{O}$ (Alfa Aesar GmbH \& Co KG, Karlsruhe, Germany) under stirring within $4 \mathrm{~h}$ at room temperature. Then, the complete removal of the water was carried out in a rotary evaporator at $70^{\circ} \mathrm{C}$. Using $\mathrm{CP}$ method, mixed solutions of $\mathrm{Ce}\left(\mathrm{NO}_{3}\right)_{3} \cdot 6 \mathrm{H}_{2} \mathrm{O}$ and $\mathrm{Y}\left(\mathrm{NO}_{3}\right)_{3} \cdot 6 \mathrm{H}_{2} \mathrm{O}$ at a necessary amounts were co-precipitated with a solution of $\mathrm{K}_{2} \mathrm{CO}_{3}$ under the conditions described above for precipitation of bare ceria. The precipitates were subjected to aging at $60^{\circ} \mathrm{C}$ for $1 \mathrm{~h}$ under stirring. Further, the precipitates were filtered and washed carefully until absence of $\mathrm{NO}_{3}{ }^{-}$ions. The thermal treatment included drying in vacuum at $80^{\circ} \mathrm{C}$ and calcination at $400{ }^{\circ} \mathrm{C}$ for $2 \mathrm{~h}$. Depending on the preparation route, the supports were labeled as $x$ YCeIM and $x \mathrm{YCeCP}$, where $x$ corresponded to the wt. $\%$ of $\mathrm{Y}_{2} \mathrm{O}_{3}$, i.e., $1,2.5,5$ and 7.5 .

Gold catalysts ( $3 \mathrm{wt}$. \%) were prepared by deposition-precipitation method. Gold was deposited onto the supports preliminary suspended in water by ultrasound. The interaction between aqueous solution of gold precursor $\left(\mathrm{HAuCl}_{4} \cdot 3 \mathrm{H}_{2} \mathrm{O}, 49.81 \% \mathrm{Au}\right.$, Johnson Matthey, Hertfordshire, England) and $\mathrm{K}_{2} \mathrm{CO}_{3}$ was performed at constant $\mathrm{pH}=7.0$ and temperature of $60^{\circ} \mathrm{C}$ in an "Contalab" automated laboratory reactor (Contraves, AG Switzerland) under full control of synthesis parameters (temperature, $\mathrm{pH}$, reactant feed flow rates, stirring speed, etc.). After filtering and careful washing, the precursors underwent the same thermal treatment as supports. The gold catalysts were labeled as AuxYCeIM and $\mathrm{Au} x \mathrm{YCeCP}$, correspondingly.

All the initial salts used were "analytical grade".

\subsection{Sample Characterization}

The BET surface area of the samples $\left(\mathrm{S}_{\mathrm{BET}}\right)$ was measured by Carlo Erba Sorptomatic 1900 instrument (Milan, Italy) with fully computerized analysis of the isotherm of $\mathrm{N}_{2}$ adsorption at $-196^{\circ} \mathrm{C}$. The standard pressure used was in the range $0.05-0.3 \mathrm{p} / \mathrm{p}_{\mathrm{o}}$. The samples were outgassed for $30 \mathrm{~min}$ at $200^{\circ} \mathrm{C}$ under vacuum before the $S_{B E T}$ determination.

The actual gold loading was measured by means of Atomic Absorption spectroscopy on an apparatus Varian Vista MPX. It was found the presence of $3( \pm 0.05)$ wt. \% gold for each catalyst. 
Powder diffraction data (XRD) were collected with D5000 diffractometer (Bruker AXS, Karlsruhe, Germany). The setup used Cu sealed tube ( $40 \mathrm{kV}, 40 \mathrm{~mA})$, Bragg-Brentano focusing geometry, slits set for 1 deg. beam divergence and 192 strips silicon strip detector (LynxEye from Bruker AXS, Karlsruhe, Germany). The diffraction patterns were analyzed with help of PeakFit program (Jandel Scientific, Corte Madera, CA, USA) as well as using Fityk (Copyright 2001-2014 Marcin Wojdar, Warszawa, Poland) to fit the XRD maxima $\left(K_{\alpha} 1,2\right)$ of PEARSON VII analytical form. Ceria crystallographic phase had estimated its lattice constant, crystal size and strain using 14 measured reflections via extrapolation as well as Williamson Hall plot $[35,36]$. The crystal size refers to a volume weighted average value of the ordered atom column length over all crystallographic directions represented by the peak Miller indices. The gold crystallite size estimation posed difficult problem due to low intensity of fcc Au peaks. In most cases only 111 peak detectable on the slope of ceria reflection was available to analysis. Then the challenging problem is the peak background estimation. We based on the wide angle fit of ceria peaks and smooth polynomial background. For the analysis of the remaining Au intensities we attempted to use peak intensity estimates from the weighted contents of $\mathrm{Au}$ in the sample and subsequent determination of the integral width of the peak (the peak area divided by its height). The latter value is known to be less dependent on the width and shape of the size distribution.

Thermogravimetric analyses (TGA) were performed with a TGA/DSC1 STAR system (Mettler Toledo AG, Schwerzenbach, Switzerland). A first series of experiments were carried out as it follows: the sample $(20 \mathrm{mg})$ was pretreated in $\mathrm{N}_{2}\left(99.999 \%\right.$ Rivoira, Milan, Italy, $\left.30 \mathrm{~mL} \cdot \mathrm{min}^{-1}\right)$ from room temperature (r.t.) to $200^{\circ} \mathrm{C}$ (rate $5^{\circ} \mathrm{C} / \mathrm{min}$ ) and cooled down to r.t. (rate $10^{\circ} \mathrm{C} / \mathrm{min}$ ) (step 1); then it was heated under pure air $\left(99.999 \%\right.$ Rivoira, Milan, Italy, $\left.30 \mathrm{~mL} \cdot \mathrm{min}^{-1}\right)$ from r.t. to $200^{\circ} \mathrm{C}$ or to $350^{\circ} \mathrm{C}$ (treatment labeled 200 or 350, respectively) (holding time $1 \mathrm{~h}$ ) (step 2). The cooling down step to r.t. was performed still under air (step 3). All the physisorbed oxygen was removed by purging at r.t. with $\mathrm{N}_{2}\left(99.999 \%\right.$ Rivoira, Milan, Italy, $30 \mathrm{~mL} \cdot \mathrm{min}^{-1}$ ) for $30 \mathrm{~min}$ (step 4). After that, the temperature programmed desorption was started under $\mathrm{N}_{2}\left(99.999 \%\right.$ Rivoira, Milan, Italy, $\left.30 \mathrm{~mL} \cdot \mathrm{min}^{-1}\right)$ by heating (rate $5{ }^{\circ} \mathrm{C} / \mathrm{min}$ ) from room temperature up to $500{ }^{\circ} \mathrm{C}$ (step 5). Step 1 under $\mathrm{N}_{2}$ was performed in order to remove any adsorbed water or carbonate species; steps 2, 3 aimed oxygen chemisorption; step 4 under $\mathrm{N}_{2}$ removed all the physisorbed oxygen species; the weight loss due to the removal of chemisorbed oxygen species occurring during step 5 was taken into account in order to evaluate the catalyst oxygen affinity. In order to monitor the evolution of gaseous species occurring during the above mentioned steps, mass quadrupole spectra were registered by using an online instrument (Thermostar ${ }^{\mathrm{TM}}$, Balzers, Liechtenstein). Such spectra were denoted in the text as QM spectra.

PHI 5000 VersaProbe (ULVAC-PHI, Inc. 370 Enzo, Chigasaki, Kanagawa, Japan) spectrometer with monochromatic Al-K $\alpha$ radiation $(\mathrm{h} v=1486.6 \mathrm{eV})$ from an X-ray source operating at $100 \mu \mathrm{m}$ spot size, $25 \mathrm{~W}$ and $15 \mathrm{kV}$ was used for the registration of the XP spectra. The analyzer pass energy was $23.5 \mathrm{eV}$, an electron take-off angle was $45^{\circ}$ and the energy step size was $0.1 \mathrm{eV}$. Prior to the analysis the samples were pressed into thin wafers and degassed in a load lock chamber. The XPS data were evaluated using CasaXPS software (Neal Fairley, Casa Software Ltd. 26 Burford Crescent, Wilmslow, Cheshire, Sk9 6BN, UK) and set of sensitivity factors supplied by PHI. The decomposition of all HR XP spectra was performed using a Shirley background subtraction and a Gaussian peak shape with $30 \%$ Lorentzian character. In order to correct the charging effects, the Ce $3 \mathrm{~d}_{3 / 2}$ peak (usually described as the $\mathrm{u}^{\prime \prime}$ peak) was adjusted to a position of $916.65 \mathrm{eV}$ as a medium value from 24 reliable publications [37-60].

The TPR experiments were performed at atmospheric pressure in temperature range from 10 to $250^{\circ} \mathrm{C}$. The water as a product of reduction was removed by cooling trap $\left(-40^{\circ} \mathrm{C}\right)$ installed before the thermal conductivity detector. The apparatus is described in more details elsewhere [61]. The reducing gas was $10 \% \mathrm{H}_{2}$ in argon (dried by a trap with molecular sieve $5 \mathrm{~A}$ at $-40{ }^{\circ} \mathrm{C}$ ). The flow rate was $24 \mathrm{~mL} \cdot \mathrm{min}^{-1}$ and the rate of linear temperature increasing was $15^{\circ} \mathrm{C} \cdot \mathrm{min}^{-1}$. On the basis of Monti and Baiker criterion [62] the used amount of the tested sample was $0.05 \mathrm{~g}$. The thermal conductivity detector was preliminary calibrated by reduction of various amounts of stoichiometric $\mathrm{NiO}$ to $\mathrm{Ni}^{0}$. 
The NiO was 'analytical grade'. The deconvolution of complex TPR spectra of selected samples was performed on the basis of the simulation of the individual reduction processes and evaluation of their kinetic parameters. Munteanu et al. ([28] and references therein) have described in more details the procedure for kinetic parameters evaluation. Their analysis will be a topic for further study.

\subsection{Catalytic Test in $\mathrm{CBO}$}

The catalytic test in $\mathrm{CBO}$ was performed at atmospheric pressure in temperature range from 150 to $320{ }^{\circ} \mathrm{C}$ using a microcatalytic continuous flow fixed bed reactor. The products were analyzed by gas chromatograph (Hewlett Packard 5890, Agilent 5890A series II, Germany, working with Agilent G2070 Chemstation Software, Germany) supplied with flame ionization detector and capillary HP Plot Q column, expedient for separating the eventual products of incomplete benzene oxidation. The used inlet benzene ( $\geqslant 99.9 \%$, Sigma-Aldrich, Saint Louis, MO, USA) concentration in air was $42 \mathrm{~g} \cdot \mathrm{m}^{-3}$, which is about 10 times higher than the concentration typically found in industrial processes. The space velocity was $4000 \mathrm{~h}^{-1}$. The catalyst bed volume was $0.5 \mathrm{~cm}^{3}$. The catalyst amount and particles size $(0.25-0.50 \mathrm{~mm})$ were enough small in order to avoid the impact of bulk and pore diffusion.

The catalysts were pretreated "in situ" during $1 \mathrm{~h}$ in a flow of purified air at two different temperatures: $200^{\circ} \mathrm{C}$ or $350{ }^{\circ} \mathrm{C}$.

\section{Conclusions}

The results of complete benzene oxidation over gold catalysts on lightly Y-doped ceria supports prepared by CP or IM showed that the best performance was that of the catalyst on the IM support with a $1 \%$ Y-dopant amount. A positive role of air pretreatment at $350{ }^{\circ} \mathrm{C}$ as compared to $200{ }^{\circ} \mathrm{C}$ was established for all Y-containing catalysts and it was explained by cleaning the active sites from carbonates. A correlation between the catalytic activity and the amount of released oxygen, measured during $\mathrm{O}_{2}$-TPD of the corresponding gold catalysts, except for the $7.5 \% \mathrm{Y}_{2} \mathrm{O}_{3}$ doping, was not established. Only in the last case did the oxygen supply become important and the observed dependence of the $\mathrm{CBO}$ activity on the preparation method was explained on the basis of the catalysts' reducibility. The XPS results of fresh catalysts and those used in $\mathrm{CBO}$ revealed that the cationic gold species cannot be considered important for high CBO activity. The $100 \%$ benzene conversion was reached over the gold catalyst on the IM support with a 1\% Y-dopant amount and Au/ceria; however, full conversion was not achieved over all other catalysts, even at $300{ }^{\circ} \mathrm{C}$. The gold and ceria particle agglomeration or coke formation should be excluded as a possible reason. The most probable explanation could be associated with the importance of the benzene activation stage, along with the enhanced surface reoxidation of the most active catalyst.

Acknowledgments: The support by the COST Action CM 1104 is gratefully acknowledged. The authors thank Y. Karakirova, IC-BAS, for the performed EPR measurements.

Author Contributions: Lyuba Ilieva, Leonarda F. Liotta and Tatyana Tabakova contributed to the data interpretation and discussion. The manuscript was written by Lyuba Ilieva. Petya Petrova performed the synthesis of catalysts, the TPR experiments and the catalytic tests in CBO. Leonarda F. Liotta performed the experiments and analyzed the TGA data. Janusz W. Sobczak and Wojciech Lisowski performed the experiments and analyzed the XPS data. Zbigniew Kaszkur contributed to the XRD characterization. Gabriel Munteanu contributed to the explanation of the reduction behavior.

Conflicts of Interest: The authors declare no conflict of interest.

\section{References}

1. Scire, S.; Liotta, L.F. Supported gold catalysts for the total oxidation of volatile organic compounds. Appl. Catal. B 2012, 125, 222-246. [CrossRef]

2. Scirè, S.; Minicò, S.; Crisafulli, C.; Satriano, C.; Pistone, A. Catalytic combustion of volatile organic compounds on gold/cerium oxide catalysts. Appl. Catal. B 2003, 40, 43-49. [CrossRef] 
3. Centeno, M.A.; Paulis, M.; Montes, M.; Odriozola, J.A. Catalytic combustion of volatile organic compounds on $\mathrm{Au} / \mathrm{CeO}_{2} / \mathrm{Al}_{2} \mathrm{O}_{3}$ and $\mathrm{Au} / \mathrm{Al}_{2} \mathrm{O}_{3}$ catalysts. Appl. Catal. A 2002, 234, 65-78. [CrossRef]

4. Lai, S.Y.; Qiu, Y.F.; Wang, S.J. Effects of the structure of ceria on the activity of gold/ceria catalysts for the oxidation of carbon monoxide and benzene. J. Catal. 2006, 237, 303-313. [CrossRef]

5. Ousmane, M.; Liotta, L.F.; Di Carlo, G.; Pantaleo, G.; Venezia, A.M.; Deganello, G.; Retailleau, L.; Boreave, A.; Giroir-Fendler, A. Supported Au catalysts for low temperature abatement of propene and toluene, as model VOCs: Support effect. Appl. Catal. B 2011, 101, 629-637. [CrossRef]

6. Jiang, X.; Hua, J.; Deng, H.; Wu, Z. Influence of pre-added $\mathrm{NaOH}$ on the microstructure of $\mathrm{Au}-\mathrm{CeO}_{2}$ catalyst and its activity for benzene oxidation. J. Mol. Catal. A: Chem. 2014, 383-384, 188-193. [CrossRef]

7. Andreeva, D.; Nedyalkova, R.; Ilieva, L.; Abrashev, M.V. Nanosize gold-ceria catalysts promoted by vanadia for complete benzene oxidation. Appl. Catal. A 2003, 246, 2938. [CrossRef]

8. Andreeva, D.; Nedyalkova, R.; Ilieva, L.; Abrashev, M.V. Gold-vanadia catalysts supported on ceria-alumina for complete benzene oxidation. Appl. Catal. B 2004, 52, 157-165. [CrossRef]

9. Andreeva, D.; Petrova, P.; Ilieva, L.; Abrashev, M.V. Gold supported on ceria and ceria-alumina promoted by molybdena for complete benzene oxidation. Appl. Catal. B 2006, 67, 237-245. [CrossRef]

10. Andreeva, D.; Petrova, P.; Ilieva, L.; Sobczak, J.W.; Abrashev, M.V. Design of new gold catalysts supported on mechanochemically activated ceria-alumina, promoted by molybdena for complete benzene oxidation. Appl. Catal. B 2008, 77, 364-372. [CrossRef]

11. Yang, S.M.; Liu, D.M.; Liu, S.Y. Catalytic Combustion of Benzene over Au Supported on Ceria and Vanadia Promoted Ceria. Top. Catal. 2008, 47, 101-108. [CrossRef]

12. Ilieva, L.; Petrova, P.; Tabakova, T.; Zanella, R.; Abrashev, M.V.; Sobczak, J.W.; Lisowski, W.; Kaszkur, Z.; Andreeva, D. Relationship between structural properties and activity in complete benzene oxidation over $\mathrm{Au} / \mathrm{CeO}_{2}-\mathrm{CoO}_{\mathrm{x}}$ catalysts. Catal. Today 2012, 187, 30-38. [CrossRef]

13. Petrova, P.; Tabakova, T.; Munteanu, G.; Zanella, R.; Tsvetkov, M.; Ilieva, L. Gold catalysts on Co-doped ceria for complete benzene oxidation: Relationship between reducibility and catalytic activity. Catal. Commun. 2013, 36, 84-88. [CrossRef]

14. Ilieva, L.; Petrova, P.; Tabakova, T.; Zanella, R.; Kaszkur, Z. Gold catalysts on ceria doped with MeOx $(\mathrm{Me}=\mathrm{Fe}, \mathrm{Mn}, \mathrm{Co}$ and $\mathrm{Sn}$ ) for complete benzene oxidation: Effect of composition and structure of the mixed supports. React. Kinet. Mech. Catal. 2012, 105, 23-37. [CrossRef]

15. Ilieva, L.; Petrova, P.; Pantaleo, G.; Zanella, R.; Liotta, L.F.; Georgiev, V.; Boghosian, S.; Kaszkur, Z.; Sobczak, J.W.; Lisowski, W.; et al. Gold catalysts supported on Y-modified ceria for CO-free hydrogen production via PROX. Appl. Catal. B 2016, 188, 154-168. [CrossRef]

16. Ou, D.R.; Mori, T.; Ye, F.; Takahashi, M.; Zou, J.; Drennan, J. Microstructures and electrolytic properties of yttrium-doped ceria electrolytes: Dopant concentration and grain size dependences. Acta Mater. 2006, 54, 3737-3746. [CrossRef]

17. Burbano, M.; Norberg, S.T.; Hull, S.; Eriksson, S.G.; Marroccelli, D.; Madden, P.A.; Watson, G.W. Oxygen vacancy ordering and the conductivity maximum in $\mathrm{Y}_{2} \mathrm{O}_{3}$-doped $\mathrm{CeO}_{2}$. Chem. Mater. 2011, 24, $222-229$. [CrossRef]

18. Yan, P.F.; Mori, T.; Suzuki, A.; Wu, Y.Y.; Auchterlonie, G.J.; Zou, J.; Drennan, J. Grain boundary's conductivity in heavily yttrium doped ceria. Solid State Ion. 2012, 222-223, 31-37. [CrossRef]

19. Vayssilov, G.N.; Mihaylov, M.; Petkov, P.S.; Hadjiivanov, K.I.; Neyman, K.M. Reassignment of the Vibrational Spectra of Carbonates, Formates, and Related Surface Species on Ceria: A Combined Density Functional and Infrared Spectroscopy Investigation. J. Phys. Chem. C 2011, 115, 23435-23454. [CrossRef]

20. Trovarelli, A. Catalytic Properties of Ceria and $\mathrm{CeO}_{2}-$ Containing Materials. Catal. Rev. Sci. Eng. 1996, 38, 439-520. [CrossRef]

21. Ying, F.; Wang, S.; Au, C.-T.; Lai, S.-Y. Highly active and stable mesoporous $\mathrm{Au} / \mathrm{CeO}_{2}$ catalysts prepared from MCM-48 hard-template. Microporous Mesoporous Mater. 2011, 142, 308-315. [CrossRef]

22. Ilieva, L.; Petrova, P.; Ivanov, I.; Munteanu, G.; Boutonnet, M.; Sobczac, J.W.; Lisowski, W.; Kaszkur, Z.; Markov, P.; Venezia, A.M.; et al. Nanosized gold catalysts on Pr-modified ceria for pure hydrogen production via WGS reaction. Mat. Chem. Phys. 2015, 157, 138-146. [CrossRef]

23. Yao, H.C.; Yao, Y.F.Y. Ceria in automotive exhaust catalysts: I. Oxygen storage. J. Catal. 1984, 86, $254-265$. [CrossRef] 
24. Fu, Q.; Weber, A.; Flytzani-Stephanopoulos, M. Nanostructured $\mathrm{Au}-\mathrm{CeO}_{2}$ catalysts for low-temperature water-gas shift. Catal. Lett. 2001, 77, 87-95. [CrossRef]

25. Andreeva, D.; Idakiev, V.; Tabakova, T.; Ilieva, L.; Falaras, P.; Bourlinos, A.; Travlos, A. Low-temperature water-gas shift reaction over $\mathrm{Au} / \mathrm{CeO}_{2}$ catalysts. Catal. Today 2002, 72, 51-57. [CrossRef]

26. Sanchez, M.G.; Gazquez, J.L. Oxygen vacancy model in strong metal-support interaction. J. Catal. 1987, 104, 120-135. [CrossRef]

27. Laachir, A.; Perrichon, V.; Bardi, A.; Lamotte, J.; Catherine, E.; Lavalley, J.C.; El Faallah, J.; Hilaire, L.; Le Normand, F.; Quemere, E.; et al. Reduction of $\mathrm{CeO}_{2}$ by hydrogen. Magnetic susceptibility and Fourier-transform infrared, ultraviolet and X-ray photoelectron spectroscopy measurements. J. Chem. Soc. Faraday Trans. 1991, 87, 1601-1609. [CrossRef]

28. Munteanu, G.; Ilieva, L.; Nedyalkova, R.; Andreeva, D. Influence of gold on the reduction behaviour of $\mathrm{Au}-\mathrm{V}_{2} \mathrm{O}_{5} / \mathrm{CeO}_{2}$ catalytic systems: TPR and kinetic parameters of reduction. Appl. Catal. A 2004, 277, 31-40. [CrossRef]

29. Guzman, J.; Corma, A. Nanocrystalline and mesostructured $\mathrm{Y}_{2} \mathrm{O}_{3}$ as supports for gold catalysts. Chem. Commun. 2005, 743-745. [CrossRef] [PubMed]

30. Carabineiro, S.A.C.; Chen, X.; Martynyuk, O.; Bogdanchikova, N.; Avalos-Borja, M.; Pestryakov, A.; Tavares, P.B.; Órfão, J.J.M.; Pereira, M.F.R.; Figueiredo, J.L. Gold supported on metal oxides for volatile organic compounds total oxidation. Catal. Today 2015, 244, 103-114. [CrossRef]

31. Monte, M.; Munuera, G.; Costa, D.; Conesa, J.C.; Martínez-Arias, A. Near-ambient XPS characterization of interfacial copper species in ceria-supported copper catalysts. Phys. Chem. Chem. Phys. 2015, 17, 29995-30004. [CrossRef] [PubMed]

32. Óvári, L.; Calderon, S.K.; Lykhach, Y.; Libuda, J.; Erdőhelyi, A.; Papp, C.; Kiss, J.; Steinrück, H.-P. Near ambient pressure XPS investigation of the interaction of ethanol with $\mathrm{Co} / \mathrm{CeO}_{2}\left(\begin{array}{ll}1 & 1\end{array}\right)$. J. Catal. 2013, 307, 132-139. [CrossRef]

33. Gamarra, D.; López Cámara, A.; Monte, M.; Rasmussen, S.B.; Chinchilla, L.E.; Hungría, A.B.; Munuera, G.; Gyorffy, N.; Schay, Z.; Corberán, V.C.; et al. Preferential oxidation of $\mathrm{CO}$ in excess $\mathrm{H}_{2}$ over $\mathrm{CuO} / \mathrm{CeO}_{2}$ catalysts: Characterization and performance as a function of the exposed face present in the $\mathrm{CeO}_{2}$ support. Appl. Catal. B 2013, 130-131, 224-238. [CrossRef]

34. Tidahy, V.; Siffert, S.; Lamonier, J.-F.; Cousin, R.; Zhilinskaya, E.A.; Aboukais, A.; Su, B.-L.; Canet, X.; De Weireld, G.; Frere, M.; et al. Influence of the exchanged cation in Pd/BEA and Pd/FAU zeolites for catalytic oxidation of VOCs. Appl. Catal. B 2007, 70, 377-383. [CrossRef]

35. Williamson, G.K.; Hall, W.H. X-ray line broadening from filed aluminium and wolfram. Acta Metall. 1953, 1, 22-31. [CrossRef]

36. Mote, V.D.; Purushotham, Y.; Dole, B.N. Williamson-Hall analysis in estimation of lattice strain in nanometer-sized ZnO particles. J. Theor. Appl. Phys. 2012, 6, 6-28. [CrossRef]

37. Barr, L.; Fries, G.; Cariati, F.; Bart, C.J.; Giordano, N. A spectroscopic investigation of cerium molybdenum oxides. J. Chem. Soc. Dalton Trans. 1983, 9, 1825-1829. [CrossRef]

38. Paparazzo, E.; Ingo, G.M.; Zaccheti, N. X-ray induced reduction effects at $\mathrm{CeO}_{2}$ surfaces: An X-ray photoelectron spectroscopy study. J. Vac. Sci. Technol. A 1991, 9, 1416-1420. [CrossRef]

39. Trudeau, M.L.; Tschope, A.; Ying, J.Y. XPS investigation of surface oxidation and reduction in nanocrystalline $\mathrm{Ce}_{x} \mathrm{La}_{1-x} \mathrm{O}_{2-y}$. Surf. Interface Anal. 1995, 23, 219-226. [CrossRef]

40. Sundaram, K.B.; Wahid, P.F.; Melendez, O. Deposition and X-ray photoelectron spectroscopy studies on sputtered cerium dioxide thin films. J. Vac. Sci. Technol. A 1997, 15, 52-56. [CrossRef]

41. Nelson, A.E.; Graves-Brook, M.K.; Schulz, K.H. Analysis of Cerium-Zirconium Mixed Metal Oxides by X-Ray Photoelectron Spectroscopy. Surf. Sci. Spectra 2001, 8, 126. [CrossRef]

42. He, H.; Dai, H.X.; Wong, K.W.; Au, C.T. $\mathrm{RE}_{0.6} \mathrm{Zr}_{0.4-x} \mathrm{Y}_{x} \mathrm{O}_{2}(\mathrm{RE}=\mathrm{Ce}, \mathrm{Pr} ; x=0$, 0.05) solid solutions: An investigation on defective structure, oxygen mobility, oxygen storage capacity, and redox properties. Appl. Catal. A 2003, 251, 61-74. [CrossRef]

43. Borchert, H.; Frolova, Y.V.; Kaichev, V.V.; Prosvirin, I.P.; Alikina, G.M.; Lukashevich, A.I.; Zaikovskii, V.I.; Moroz, E.M.; Trukhan, S.N.; Ivanov, V.P.; et al. Electronic and Chemical Properties of Nanostructured Cerium Dioxide Doped with Praseodymium. J. Phys. Chem. B 2005, 109, 5728-5738. [CrossRef] [PubMed]

44. Bêche, E.; Charvin, P.; Perarnau, D.; Abanades, S.; Flamant, G. Ce 3d XPS investigation of cerium oxides and mixed cerium oxide $\left(\mathrm{Ce}_{x} \mathrm{Ti}_{y} \mathrm{O}_{z}\right)$. Surf. Interface Anal. 2008, 40, 264-267. [CrossRef] 
45. Fang, J.; Bi, X.; Si, D.; Jiang, Z.; Huang, W. Spectroscopic studies of interfacial structures of $\mathrm{CeO}_{2}-\mathrm{TiO}_{2}$ mixed oxides. Appl. Surf. Sci. 2007, 253, 8952-8961. [CrossRef]

46. Rebellato, J.; Natile, M.; Glisenti, A. Influence of the synthesis procedure on the properties and reactivity of nanostructured ceria powders. Appl. Catal. A 2008, 339, 108-120. [CrossRef]

47. Xi, L.; Yan, S.; Zhu, L.; Li, L.; Wenhui, S. Synthesis and Properties of the Solid Solution $\mathrm{Ce}_{1-x} \operatorname{PrxO}_{2-\delta}$ $(x=0.05 \sim 0.30)$. Acta Chim. Sinica 2009, 67, 1389-1394.

48. Reddy, B.M.; Thrimurthulu, G.; Katta, L.; Yamada, Y.; Park, S.E. Structural Characteristics and Catalytic Activity of Nanocrystalline Ceria-Praseodymia Solid Solutions. J. Phys. Chem. C 2009, 113, 15882-15890. [CrossRef]

49. Yu, Q.; Li, Y.; Zou, X.; Zhuo, H.; Yao, Y.; Suo, Z. Effect of Alkali Metal Promoters on Water-Gas Shift Activity over Au-Pt/ $\mathrm{CeO}_{2}$ Catalyst. Chin. J. Catal. 2010, 31, 671-676.

50. Reddy, B.M.; Lakshmi, K.; Thrimurthulu, G. Novel Nanocrystalline $\mathrm{Ce}_{1-x} \mathrm{La}_{x} \mathrm{O}_{2-\delta}(x=0.2)$ Solid Solutions: Structural Characteristics and Catalytic Performance. Chem. Mater. 2010, 22, 467-475. [CrossRef]

51. Cai, W.; Chen, F.; Shen, X.; Chen, L.; Zhang, J. Enhanced catalytic degradation of AO7 in the $\mathrm{CeO}_{2}-\mathrm{H}_{2} \mathrm{O}_{2}$ system with $\mathrm{Fe}^{3+}$ doping. Appl. Catal. B 2010, 101, 160-168. [CrossRef]

52. Kim, W.-H.; Kim, M.-K.; Maeng, W.J.; Gatineau, J.; Pallem, V.; Dussarrat, C.; Noori, A.; Thompson, D.; Chu, S.; Kim, H. Growth Characteristics and Film Properties of Cerium Dioxide Prepared by Plasma-Enhanced Atomic Layer Deposition. J. Electrochem. Soc. 2011, 158, G169. [CrossRef]

53. Paunović, N.; Dohčević-Mitrović, Z.; Scurtu, R.; Aškrabić, S.; Prekajski, M.; Matović, B.; Popović, Z.V. Suppression of inherent ferromagnetism in Pr-doped $\mathrm{CeO}_{2}$ nanocrystals. Nanoscale 2012, 4, 5469-5476. [CrossRef] [PubMed]

54. Coll, M.; Gazquez, J.; Palau, A.; Varela, M.; Obradors, X.; Puig, T. Low Temperature Epitaxial Oxide Ultrathin Films and Nanostructures by Atomic Layer Deposition. Chem. Mater. 2012, 24, 3732-3737. [CrossRef]

55. Gong, L.; Luo, L.-T.; Wang, R.; Zhang, N. Effect of preparation method of $\mathrm{CeO}_{2}-\mathrm{MnO}_{x}$ mixed oxides $\mathrm{n}$ preferential oxidation of $\mathrm{CO}$ in $\mathrm{H}_{2}$-rich gases over $\mathrm{CuO}$-based catalysts. J. Chil. Chem. Soc. 2012, 57, 1048-1053. [CrossRef]

56. Beche, E.; Peraudeau, G.; Flaud, V.; Perarnau, D. An XPS investigation of $\left(\mathrm{La}_{2} \mathrm{O}_{3}\right)_{1-x}\left(\mathrm{CeO}_{2}\right)_{2 x}\left(\mathrm{ZrO}_{2}\right)_{2}$ compounds. Surf. Interface Anal. 2012, 44, 1045-1050. [CrossRef]

57. Tan, J.; Zhang, W.; Lv, Y.-H.; Xia, A.-L. Facile Preparation of Mn-doped $\mathrm{CeO}_{2}$ Submicrorods by Composite-Hydroxide-Salt-Mediated Approach and Their Magnetic Property. Mater. Res. 2013, 16, 689-694. [CrossRef]

58. Konysheva, E.Y.; Francis, S.M. Identification of surface composition and chemical states in composites comprised of phases with fluorite and perovskite structures by X-ray photoelectron spectroscopy. Appl. Surf. Sci. 2013, 268, 278-287. [CrossRef]

59. Santra, C.; Rahman, S.; Bojja, S.; James, O.; Sen, D.; Maity, S.; Mohanty, A.K.; Mazumder, S.; Chowdhury, B. Barium, calcium and magnesium doped mesoporous ceria supported gold nanoparticle for benzyl alcohol oxidation using molecular $\mathrm{O}_{2}$. Catal. Sci. Technol. 2013, 3, 360-370. [CrossRef]

60. Alshankiti, I.; Al-Otaibi, F.; Alsalik, Y.; Idriss, H. Solar Thermal Hydrogen Production from Water over Modified $\mathrm{CeO}_{2}$ Materials. Top. Catal. 2013, 56, 1129-1138. [CrossRef]

61. Kotzev, N.; Shopov, D. A thermodesorption study of the system olefin-NiO. J. Catal. 1971, 22, $297-301$. [CrossRef]

62. Monti, D.A.M.; Baiker, A. Temperature-programmed reduction. Parametric sensitivity and estimation of kinetic parameters. J. Catal. 1983, 83, 323-335. [CrossRef]

(C) 2016 by the authors; licensee MDPI, Basel, Switzerland. This article is an open access article distributed under the terms and conditions of the Creative Commons Attribution (CC-BY) license (http://creativecommons.org/licenses/by/4.0/). 